\title{
Clinical usefulness of iQ200/iChem Velocity workstation for screening of urine culture
}

\author{
Jong-Mi Lee, Doo-Jin Baek, Kang Gyun Park, Eunhee Han and Yeon-Joon Park
}

\begin{abstract}
Background: Clinical microbiology laboratories are asked to process large numbers of urine specimens for culture, but only $20-40 \%$ of them are positive. Therefore, a rapid, reliable screening method is necessary to speed up the reporting of a negative result. In this study, we evaluated the iQ200/iChem workstation, which is a combination of digital imaging software and a strip reader to predict negative urine culture.

Method: A total of 1942 urine specimens were processed through both culture and iQ200/ iChem workstation. We analyzed the performance using two definition of positive urine culture; one or two potential uropathogens at a concentration of $\geq 10^{5} \mathrm{CFU} / \mathrm{ml}$ and $\geq 10^{4} \mathrm{CFU} / \mathrm{ml}$. We assessed combinations of parameters (ASP; all small particles, WBC; leukocyte, BACT; bcteria, LE; leukocyte esterase) applying various cut-offs which can achieve the negative predictive value (NPV) $\geq 97 \%$ and culture reduction rate $\geq 50 \%$.

Results: The culture positive rate was 12.8 and $18.4 \%$ applying the criteria of $\geq 10^{5} \mathrm{CFU} / \mathrm{ml}$ and $\geq 10^{4} \mathrm{CFU} / \mathrm{ml}$, respectively. The area under the curve (AUC) of each parameter for $\geq 10^{5} \mathrm{CFU} / \mathrm{ml} / \geq 10^{4} \mathrm{CFU} / \mathrm{ml}$ bacteriuria was $795 / 0.719$ for WBC, 0.722 / 0.701 for ASP and $0.740 / 0.704$ for bacteria. Therefore, we investigated the combination of the parameters. With the fixed parameter of BACT $\geq 1 / \mathrm{HPF}$ and positive LE, the combinations of WBC $\geq 4 / \mathrm{HPF}$ and ASP $\geq 8500 / \mu \mathrm{l}$ or WBC $\geq 6 / \mathrm{HPF}$ and $A S P \geq 5500 / \mu l$ showed good performance for detecting $\geq 10^{5} \mathrm{CFU} / \mathrm{ml}$ uropathogen. The ranges of sensitivity, specificity, negative predictive value and culture reduction rate were $91.5-92.3 \%, 49.8-52.6 \%, 97.7-97.9 \%$ and $50.4-53.0 \%$, respectively. However, none of the combined setting yielded acceptable range of NPV for detecting $\geq 10^{4} \mathrm{CFU} / \mathrm{ml}$ uropathogen (NPV 92.9-94.9\%). Enterococcus spp. was the most common uropathogen causing the false negative results (55.7\%), and also the main pathogen among the positive culture of $10^{4-5} \mathrm{CFU} / \mathrm{ml}$ bacteriuria (45\%).

Conclusions: $\mathrm{iQ200/iChem} \mathrm{workstation} \mathrm{was} \mathrm{excellent} \mathrm{in} \mathrm{detection} \mathrm{of} \geq 10^{5} \mathrm{CFU} / \mathrm{ml}$ uropathogen, but unsatisfactory in detection of $10^{4-5} \mathrm{CFU} / \mathrm{ml}$ uropathogen and Enterococcus spp. It can be useful for screening of urine specimens to reduce bacterial culture. However, notice from clinician will be necessary for specimens from the patients with high risk for UTI, such as pregnant woman, infant, elderly or immune compromised patients.
\end{abstract}

Keywords: Urinary tract infection, Urine culture, Combination, WBC and all small particles

\section{Background}

Urinary tract infection (UTI) is the most common infection in both hospitalized and community patients [1]. The indications for urine culture are 1) when signs or symptoms suggest a UTI is present 2) in patients who cannot provide clinical history (intubated, demented) and 3) have sepsis without another source to explain it [2]. However, clinical microbiology laboratories are asked to process large numbers of urine specimens for

\footnotetext{
* Correspondence: yjpk@catholic.ac.kr

Department of Laboratory Medicine, College of Medicine, Seoul St. Mary's Hospital, Catholic University of Korea, Banpodaero 222, Seocho-gu, Seoul 06591, South Korea
}

(c) The Author(s). 2019 Open Access This article is distributed under the terms of the Creative Commons Attribution 4.0 International License (http://creativecommons.org/licenses/by/4.0/), which permits unrestricted use, distribution, and reproduction in any medium, provided you give appropriate credit to the original author(s) and the source, provide a link to the Creative Commons license, and indicate if changes were made. The Creative Commons Public Domain Dedication waiver (http://creativecommons.org/publicdomain/zero/1.0/) applies to the data made available in this article, unless otherwise stated.

culture, often in the absence of clear indications, giving negative results in $60-80 \%$ of specimens [3]. Therefore, a screening method that identify negative urine culture samples and exclude them from further culture procedures could reduce the overall turnaround time, workload, and costs. However, high sensitivity and negative predictive value (NPV) should be prerequisites to prevent the true UTI-positive urine specimens from not being cultured. Many screening methods have been introduced and evaluated for a long time. Gram staining is rapid and economical, but labor intensive and trained technologists are required. Moreover, it is not sensitive, 
and requires the concentration of bacteria more than $10^{5} \mathrm{CFU} / \mathrm{ml}$ in the urine [4]. Dipstick tests for leukocyte esterase and nitrite are rapid, inexpensive and simple but insensitive [5]. Active researches have continued to find a reliable and cost-effective automated urine screening system to exclude urine samples from unnecessary culture processes, but no method has yet proved truly reliable. The iQ200/iChem workstation (Iris Diagnostics, Chatsworth, CA, USA) is combination of iQ200 and a strip reader, iChem Velocity. The main difference of iQ200/iChem workstation from the flow cytometer is that the urine content is analyzed by assessment of digital images of the particles passing in the front of a microscope objective. This system has recently added a new parameter, the detection of "all small particles" (ASP), to improve the sensitivity of the assay. Six parameters from the two instruments (iQ200 and iChem Velocity) are available; ASP (all small particles), WBC (white blood cells, leukocyte), BACT (bacteria), BYST (yeast), LE (leukocyte esterase) and NT (nitrite), but the best combination of them is still uncertain. In this study, we investigated the combination of parameters using various cut-off values to maximize negative predictive value (NPV) and culture reduction rate of iQ200/iChem workstation to detect UTI in the patient population of a tertiary hospital in Korea.

\section{Methods}

A total of 2530 urine samples submitted for bacterial culture from March to May 2017 to the clinical microbiology laboratory of the Seoul St. Mary's hospital were enrolled without any selection. Of them, 1942 samples which had sufficient volume $(>4 \mathrm{ml})$ were included. They were from outpatients or hospitalized patients, and mostly midstream urine $(1618,83.3 \%)$, followed by catheterized urine $(236,12.2 \%)$. Samples were collected in sterile containers without preservatives and transported to the laboratory within $1 \mathrm{~h}$ after collection and was stored at $4{ }^{\circ} \mathrm{C}$ for maximum of $16 \mathrm{~h}$ before being processed. Each sample was divided into two aliquots; one was used for iQ200/iChem workstation and the other was used for routine urine culture. The order on processing and urine portion for the two tests were randomly determined. The parameters reported by the instrument include ASP, WBC, BACT, BYST, LE and NT. The indicators measured by the $\mathrm{iQ200}$ module were ASP, WBC, BACT, and BYST and those by iChem Velocity were NT and LE. (The raw dataset used for this analysis can be found in Additional file 1).

This study was approved by the institutional review board (IRB) of Seoul St. Mary's Hospital. The IRB waived the requirement to obtain informed consent from participants, because we used de-identified left over samples obtained from routine examination.
Urine culture was performed using $1 \mu$ disposable loop by delivering and spreading well-mixed urine onto the blood agar plate, and MacConkey agar plate. When overgrowth of Gram-negative bacteria was observed, colistin-nalidixic acid-supplemented Columbia blood agar was additionally used. The plates were incubated under aerobic condition at $37^{\circ} \mathrm{C}$ for 16 to $24 \mathrm{~h}$. In this study, the positive urine culture result was defined as the growth of one or two potential uropathogens with a concentration of $\geq 10^{5} \mathrm{CFU} / \mathrm{ml}$ respectively. Additional analysis was also performed based on cut-off value of $\geq 10^{4} \mathrm{CFU} / \mathrm{ml}$ for comparison with the previous studies, that investigated iQ200/iChem workstation $[6,7]$. Potential uropathogens were defined as members of the family Enterobacteriaceae, Enterococcus spp., Streptococcus

Table 1 Demographic of the culture results

\begin{tabular}{|c|c|c|}
\hline $\begin{array}{l}\text { Sample Characteristics and } \\
\text { Culture results }\end{array}$ & \multicolumn{2}{|l|}{ No. of samples ${ }^{a}(\%)$} \\
\hline \multicolumn{3}{|l|}{ Growth behavior of the specimens } \\
\hline $\begin{array}{l}\text { Growth of non-uropathogen, } \\
\text { multiple bacterial morphotypes }\end{array}$ & \multicolumn{2}{|l|}{$233(12.0)$} \\
\hline No growth - culture negative & \multicolumn{2}{|l|}{$1225(63.1)$} \\
\hline $\begin{array}{l}10^{3} \sim 10^{4} \mathrm{CFU} / \mathrm{mL} \text { - culture } \\
\text { negative }\end{array}$ & \multicolumn{2}{|l|}{$127(6.5)$} \\
\hline $10^{4} \sim 10^{5} \mathrm{CFU} / \mathrm{mL}$ - culture positive & \multicolumn{2}{|l|}{$109(5.6)$} \\
\hline$\geq 10^{5} \mathrm{CFU} / \mathrm{mL}$ - culture positive & \multicolumn{2}{|l|}{$248(12.8)$} \\
\hline $\begin{array}{l}\text { Species distribution culture } \\
\text { positive samples. }\end{array}$ & $\begin{array}{l}10^{4-5} \mathrm{CFU} / \mathrm{ml} \text { total } / \\
\text { single }(\%)^{\mathrm{b}}\end{array}$ & $\begin{array}{l}\geq 10^{5} \mathrm{CFU} / \mathrm{m} \\
\text { total } / \text { single } \\
(\%)^{b}\end{array}$ \\
\hline Escherichia coli & $29 / 25(26.6)$ & $83 / 83(33.5)$ \\
\hline Enterococcus spp. & 37/36 (33.9) & $51 / 41(20.6)$ \\
\hline Candida spp. & 21/21 (19.3) & $67 / 67(27.0)$ \\
\hline Klebsiella pneumoniae & $4 / 2(3.7)$ & $17 / 10(6.9)$ \\
\hline Enterobacter spp. & $2 / 0(1.8)$ & 9/4 (3.6) \\
\hline other Enterobacteriaceae & 2/0 (1.8) & 9/1 (3.6) \\
\hline Citrobacter spp.. & $2 / 0(1.8)$ & $7 / 2(2.8)$ \\
\hline Proteus mirabilis & 2/1 (1.8) & $5 / 4(2.0)$ \\
\hline Acinetobacter baumannii complex & $0 / 0(0)$ & $6 / 5(2.4)$ \\
\hline Pseudomonas aeruginosa & $1 / 1(0.9)$ & $4 / 3(1.6)$ \\
\hline Staphylococcus aureus & 3/1 (2.8) & $2 / 2(0.1)$ \\
\hline Streptococcus agalactiae. & $3 / 2(2.8)$ & $1 / 0(0.4)$ \\
\hline Morganella morganii & $1 / 0(0.9)$ & $1 / 0(0.4)$ \\
\hline Aerococcus urinae & $1 / 0(0.9)$ & $0 / 0(0)$ \\
\hline Serratia marcescens & $0 / 0(0)$ & $1 / 0(0.4)$ \\
\hline Pasteurella aerogenes & $0 / 0(0)$ & $1 / 0(0.4)$ \\
\hline Streptococcus uberis & $0 / 0(0)$ & $1 / 0(0.4)$ \\
\hline
\end{tabular}

${ }^{a}$ The total number of samples was 1942

${ }^{\mathrm{b}}$ Total counts of the pathogen identified including mixed growth and single growth / counts of the single pathogen growth (percentage of total counts of each species divided by the number of $10^{4-5} \mathrm{CFU} / \mathrm{ml}$ - culture positive (109) or $\geq 10^{5} \mathrm{CFU} / \mathrm{mL}$ - culture positive(248)) 
Table 2 Culture results according to the gender, age, specimen types

\begin{tabular}{llll}
\hline Culture results & No. of samples (\%) & $10^{4}-10^{5} \mathrm{CFU} / \mathrm{mL}(\%)$ & $>10^{5} \mathrm{CFU} / \mathrm{mL}(\%)$ \\
\hline Gender/Age & & & $116(26.1)$ \\
Women older than 60 years old & $444(22.9)$ & $41(9.2)$ & $54(11.8)$ \\
Women between 18 and 60 years old & $459(23.6)$ & $40(6.5)$ & $1(1.2)$ \\
Women younger than 18years old & $86(4.4)$ & $4(4.6)$ & $53(12.5)$ \\
Men older than 60 years old & $423(21.8)$ & $5(1.2)$ & $19(4.5)$ \\
Men between 18 and 60 years old & $423(21.8)$ & $10(9.3)$ & $5(4.7)$ \\
Men younger than 18 years old & $107(5.5)$ & & $184(11.3)$ \\
Specimen types & & $89(5.5)$ & $64(27.1)$ \\
Midstream urine & $1618(83.3)$ & $20(8.5)$ & $0(0)$ \\
Catheterized urine & $236(12.2)$ & $0(0)$ & \\
Unknown & $88(4.5)$ &
\end{tabular}

agalactiae, Pseudomonas species, Acinetobacter baumannii complex, Candida spp., Staphylococcus aureus, Staphylococcus saprophyticus, Aerococcus urinae [8]. Grown colonies were identified by Vitek-2 system or Vitek MS (bioMerieux). Gram staining was also performed using $10 \mu \mathrm{l}$ of well-mixed, unspun urine samples. The Gram stain slides were examined by a trained technician, and the presence of WBC were determined as $\geq 1 /$ LPF [9]. First, we assessed the parameters using the manufacture-suggested abnormal thresholds for ASP $(\geq 7500 / \mu \mathrm{l})$, WBC $(\geq 6 / \mathrm{HPF})$, BYST $(\geq 1 / \mathrm{HPF})$ and BACT $(\geq 1 / \mathrm{HPF}$ ) and positive results for LE and NT (Customer Guide to iQ 200 Series Formed Particle Settings). Afterwards, we analyzed the results using the combinations of parameters applying various cut-off values which can achieve the NPV $\geq 97 \%$ and culture reduction rate $\geq 50 \%$. Receiver operating characteristics (ROC) curves were made using MedCalc (v.16.4.3), Statistical analysis was performed using SPSS software version 24.0 (SPSS Korea, Seoul, Korea). A two-tailed $P$ value $<0.05$ was considered statistically significant.

\section{Results}

During the study period 1942 samples were tested by iQ200/iChem workstation and cultured as routine process. The median age of the study population was 58 years old (range 1 days to 96 years), and 953 (49\%) of them were male. Two hundred forty-eight samples (14.5\%) revealed growth of $\geq 10^{5} \mathrm{CFU} / \mathrm{ml}$ of potential uropathogen, and the most common pathogen was Escherichia coli $(33.5 \%)$ and was followed by Candida spp. (27.0\%), Enterococcus spp. (20.6\%).

One hundred nine samples $(6.4 \%)$ showed growth of $10^{4-5} \mathrm{CFU} / \mathrm{ml}$ of potential uropathogen and the most common pathogen was Enterococcus spp. (33.9\%) and was followed by E. coli (26.6\%), Candida spp. (19.3\%) (Table 1.). Two hundred thirty-three samples showing growth of non-uropathogens $(N=109)$ or growth of more than 3 isolates $(N=124)$ were considered as negative. According to the patient group, the prevalence of positive urine cultures $\left(\geq 10^{4} \mathrm{CFU} / \mathrm{ml}\right)$ was highest in women older than 60 years old (157/444, 35.3\%), followed by women between 18 and 60 years old (84/ $459,18.3 \%)$, men older than 60 years old $(72 / 423$, $17.0 \%)$, men younger than 18 years old (15/107, 14.0\%) and lowest in men between 18 and 60 years old (24/423, $5.7 \%)$. According to the type of the urine samples, catheterized urine showed higher positive rate $(84 / 236$, $35.6 \%)$, than that of midstream urine $(273 / 1618,16.9 \%)$ (Table 2). For detecting WBCs among the culturepositive specimens $\left(\geq 10^{5} \mathrm{CFU} / \mathrm{ml} / \geq 10^{4} \mathrm{CFU} / \mathrm{ml}\right.$ bacteriuria), WBC was observed in $49.8 \% / 41.2 \%$ by Gram stain, while iQ200 showed $\geq 6 \mathrm{WBC} / \mathrm{HPF}$ in $88.5 \% / 63.1 \%$ of the culture-positive samples $\left(P<0.001\right.$ for both $\geq 10^{5}$ $\mathrm{CFU} / \mathrm{ml} / \geq 10^{4} \mathrm{CFU} / \mathrm{ml}$ bacteriuria) (Table 3 ).

Among the six parameters, as BYST and NT were not effective in detecting bacteriuria, we investigated the performance of the remaining four parameters by receiver operating characteristic curve (ROC) analysis (Fig. 1). For $\geq 10^{5} \mathrm{CFU} / \mathrm{ml}$ and $\geq 10^{4} \mathrm{CFU} / \mathrm{ml}$ of bacteriuria, WBC showed highest AUC (0.795/0.719), followed by ASP, BACT and BYST $(0.722 / 0.701,0.740 / 0.704$ and $0.667 / 0.619$, respectively). Moreover, even if the cut-off of $\mathrm{WBC} \geq 1 / \mathrm{HPF}$ was applied, $20.2 \%$ of urine culture

Table 3 Comparison of WBC detection by Gram stain and iQ200

\begin{tabular}{lll}
\hline (Gram stain) / (iQ200) & $\begin{array}{l}>10^{5} \mathrm{CFU} / \mathrm{mL}(\%) \\
(n=248)\end{array}$ & $\begin{array}{l}>10^{4} \mathrm{CFU} / \mathrm{mL}(\%) \\
(n=342)\end{array}$ \\
\hline$(+) /(+)$ & $97(40.9)$ & $113(33.0)$ \\
$(+) /(-)$ & $21(8.9)$ & $28(8.2)$ \\
$(-) /(+)$ & $89(37.6)$ & $103(30.1)$ \\
$(-) /(-)$ & $30(12.7)$ & $98(28.7)$ \\
\hline
\end{tabular}

Gram stain results were available in 1810 samples

The positive WBC result in gram stain is defined as $\geq 1 / L P F$; The positive WBC result in iQ200 is defined as $\geq 6 / \mathrm{HPF}$ 


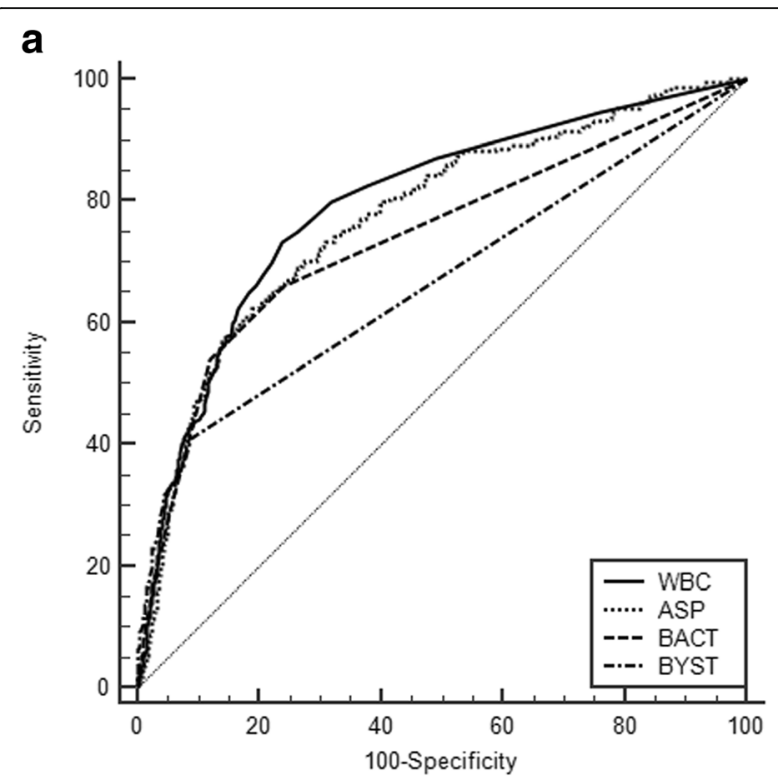

b

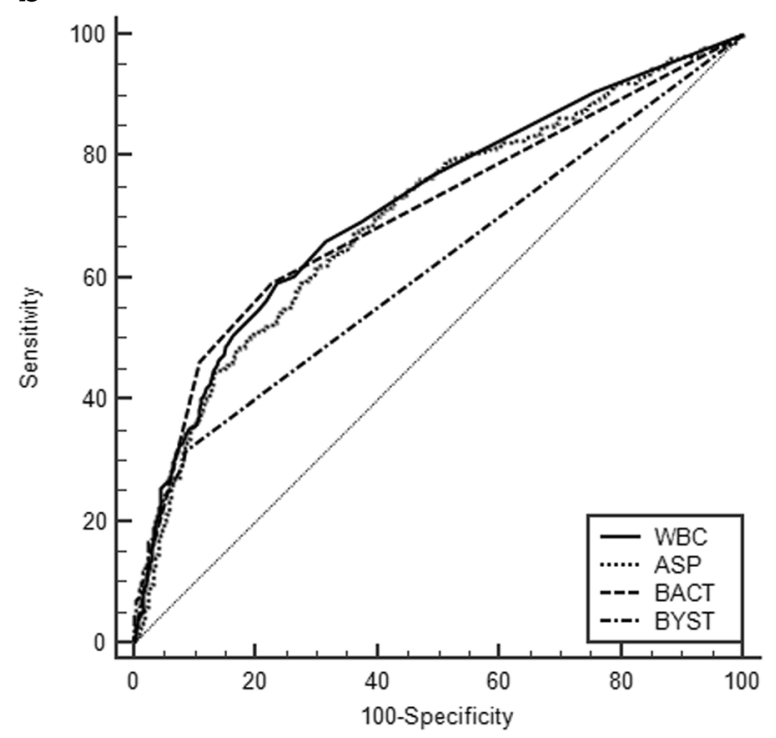

Fig. 1 Receiver operating characteristic curves of the 4 parameters. a $10^{5} \mathrm{CFU} / \mathrm{ml}$ : positive urine culture, AUC of the parameter ( $95 \%$ confidential interval); WBC 0.795 (0.777-0.813), ASP 0.722 (0.753-0.791), BACT 0.740 (0.720-0.759), BYST $0.667(0.646-0.688)$ (b) $10^{4} \mathrm{CFU} / \mathrm{ml}$ : positive urine culture, AUC of the parameter (95\% confidential interval); WBC 0.719 (0.698-0.739), ASP 0.701 (0.680-0.721), BACT 0.704 (0.6830.724), BYST 0.619 (0.597-0.641)

positive samples containing $10^{4-5} \mathrm{CFU} / \mathrm{ml}$ and $6.7 \%$ of urine culture positive samples containing $10^{5} \mathrm{CFU} / \mathrm{ml}$ will be regarded as falsely negative (Fig. 2-a). Likewise, with the cut-off value of $\mathrm{ASP} \geq 1000 / \mu \mathrm{l}$, as many as $36.0 \%$ of urine culture positive samples containing $10^{4-5} \mathrm{CFU} /$ $\mathrm{ml}$, and $11.7 \%$ of urine culture positive samples containing $10^{5} \mathrm{CFU} / \mathrm{ml}$ will be regarded as falsely negative (Fig. 2-b). According to the patient group, the adult women group showed similar pattern with the total population (Fig. 2-c,f), while the adult men groups showed the higher sensitivity than total population in both WBC and ASP (Fig. 2-g,h). Notably, the both parameters showed poor performance in patients younger than 18 years old (Fig. 2-K,L).

Because the individual parameters were not effective, we assessed the performance of the combination of $\mathrm{WBC}$ and ASP with a fixed parameters of BACT $\geq 1 / \mathrm{HPF}$ and positive LE (Fig. 3, Supplementary Table S-1,2). For $10^{5} \mathrm{CFU} / \mathrm{ml}$ bacteriuria, NPV and sensitivity were high (>97 and $>91 \%$ ) regardless of WBC or ASP cut-off value. However, to attain the culture reduction rate of $\geq 50 \%$, we chose WBC $\geq 4 / \mathrm{HPF}$ and WBC $\geq 6 / \mathrm{HPF}$. When WBC $\geq 4 /$ HPF was applied, the acceptable NPV (97.7\%) and culture reduction rate (50.4-50.5\%) were obtained at $\mathrm{ASP} \geq 8500 / \mu \mathrm{l}$. Likewise, when $\mathrm{WBC} \geq 6 / \mathrm{HPF}$ was applied, the acceptable NPV (97.7-97.9\%) and culture reduction rate $(51.4-53.0 \%)$ were obtained at $\mathrm{ASP} \geq 5500 / \mu \mathrm{l}$ (Fig. 3c-d). These combinations include the abnormal thresholds suggested by manufacturer (WBC $\geq 6 / \mathrm{HPF}$, $\mathrm{ASP} \geq 7500 / \mu \mathrm{l}, \mathrm{BACT} \geq 1 / \mathrm{HPF}$ and positive LE). By using it, the sensitivity, specificity, positive predictive value (PPV), NPV and culture reduction rate were 91.5, 51.5, 21.7, 97.7 and $52.3 \%$, respectively. False negative results were observed in 21 cases, which include 8 Enterococcus spp., 5 Escherichia coli, 3 Enterobacter spp., 3. Candida spp., and so on.

In detection of $10^{4} \mathrm{CFU} / \mathrm{ml}$ bacteriuria, none of the combined settings could achieve the acceptable NPV or culture reduction rate. By applying the manufacturer's suggested thresholds, the sensitivity, specificity, PPV, NPV and culture reduction rate were 87.4, 39.3, 24.5, 93.3 and $39.1 \%$. False negative results were observed in 61 cases, which include 34 Enterococcus spp., 14 Escherichia coli, 4 Enterobacter spp., 4. Candida spp., and so on.

\section{Discussion}

The main objective of this study was to evaluate the automated urine screening.

system to reduce the number of specimens to be cultured without excluding the true UTI.

specimens. As individual parameter showed low sensitivity, we assessed the combination of parameters. With the fixed parameter of $\mathrm{BACT} \geq 1 / \mathrm{HPF}$ and positive $\mathrm{LE}$, we found that either the combination of WBC $\geq 4 / \mathrm{HPF}+$ ASP $\geq 8500 / \mu \mathrm{l}$ or $\mathrm{WBC} \geq 6 / \mathrm{HPF}+\mathrm{ASP} \geq 5500 / \mu \mathrm{l}$, could achieve the NPV $\geq 97 \%$ and culture reduction rate of $\geq 50 \%$ in detection of $10^{5} \mathrm{CFU} / \mathrm{ml}$ bacteriuria, and the latter includes the abnormal thresholds recommended by the manufacturer.

Previous investigators reported various results in evaluation of iQ200: Parta et al. [7], reported 94.2\% NPV 
A

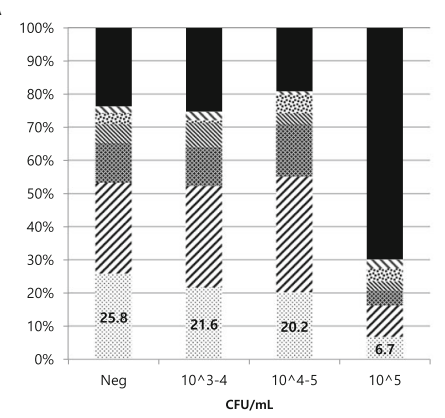

$\because 0 \mathrm{WBC} / \mathrm{HPF} \quad 21 \mathrm{WBC} / \mathrm{HPF} \approx 2 \mathrm{WBC} / \mathrm{HPF} \approx 3 \mathrm{WBC} / \mathrm{HPF}$

$\because 4 \mathrm{WBC} / \mathrm{HPF} \quad \backslash 5 \mathrm{WBC} / \mathrm{HPF} \quad \geq 6 \mathrm{WBC} / \mathrm{HPF}$

C

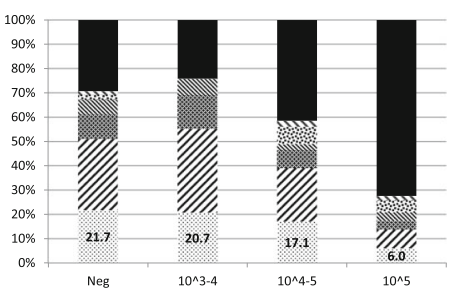

E

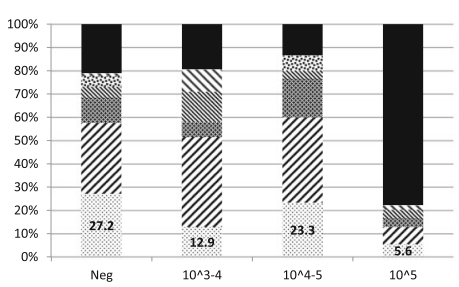

G

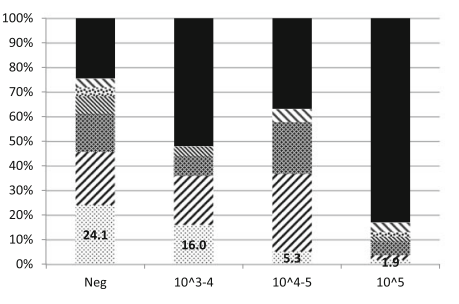

I

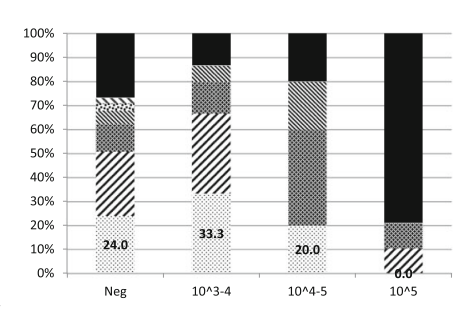

K

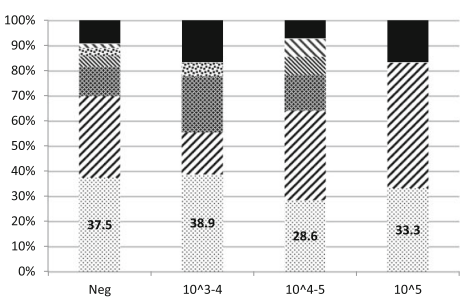

B

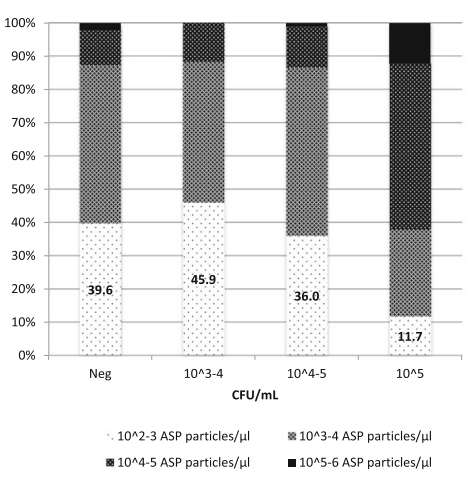

D

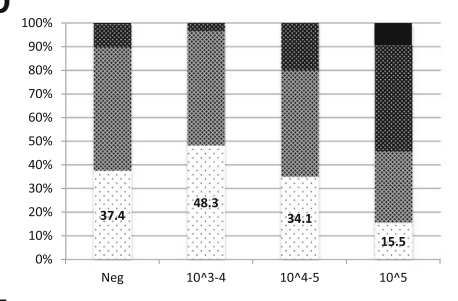

$\mathbf{F}$

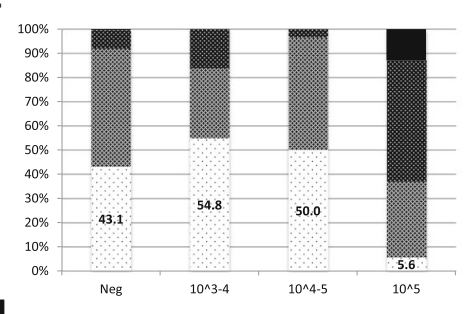

H

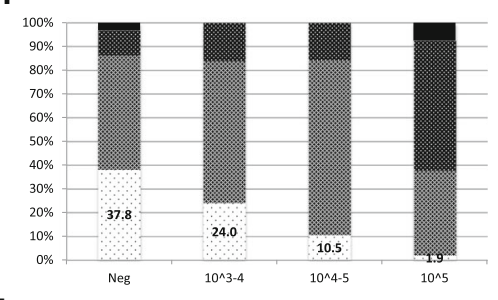

J

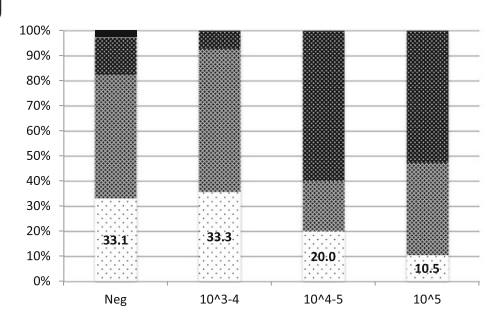

L

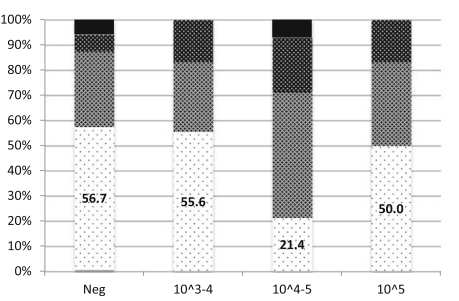

Fig. 2 Stacked bar charts of growth uropathogen versus WBC and ASP. Urine samples from total study population (a,bb), women older than 60 years old $(\mathbf{c}, \mathbf{d})$, women between 18 and 60 years old $(\mathrm{E}, \mathrm{F})$, men older than 60 years old $(\mathrm{G}, \mathrm{H})$, men between 18 and 60 years old $(\mathrm{l}, \mathrm{J})$, patients younger than 18 years old $(K, L)$ 
A

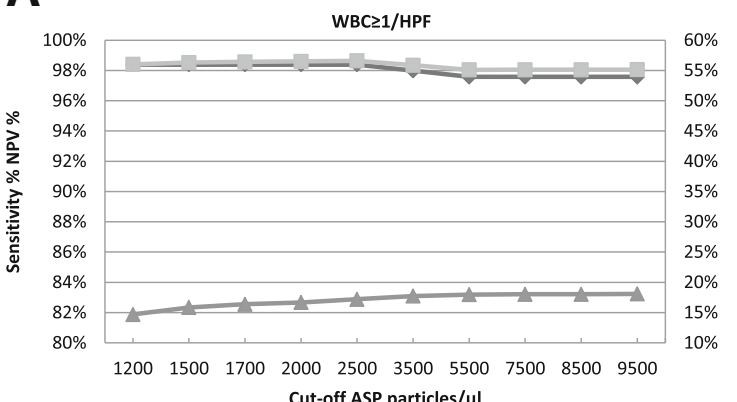

Cut-off ASP particles/ $\mu \mathrm{l}$

WBC $\geq 4 / H P F$

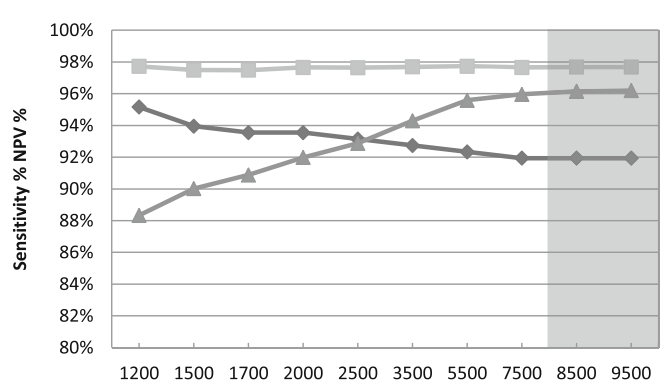

Cut-off ASP particles/ $\mu \mathrm{l}$

B

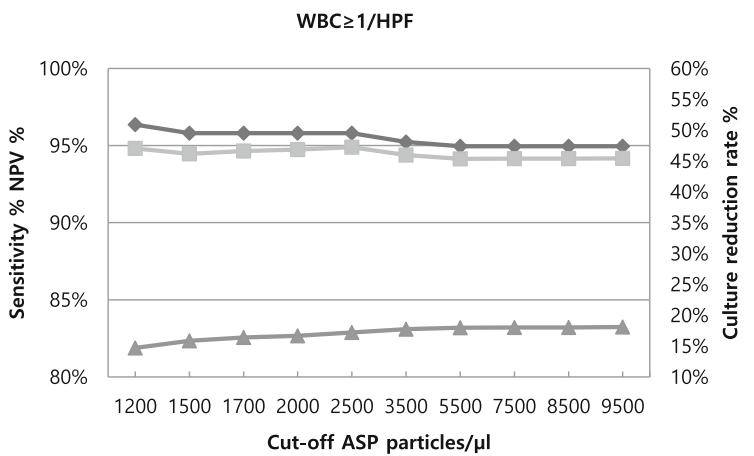

Cut-off ASP particles/ $\mu \mathrm{l}$

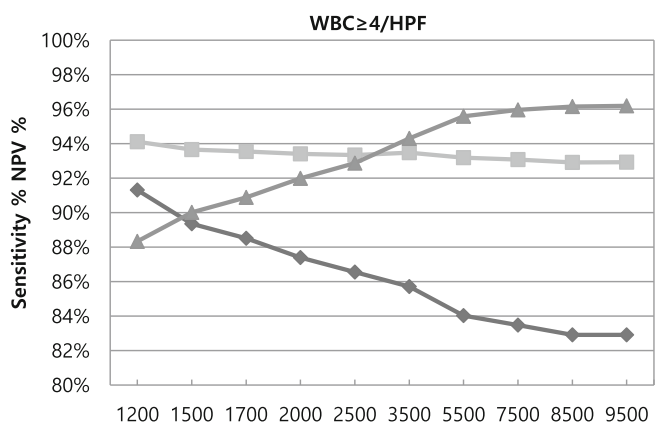

Cut-off ASP particles/ $\mu \mathrm{l}$
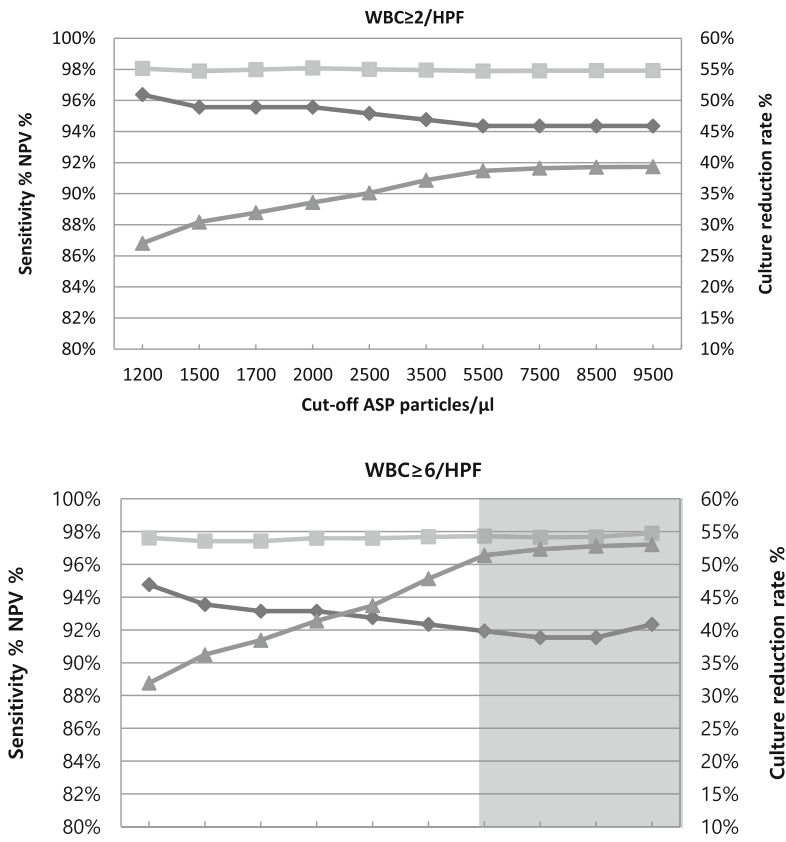

$12001500170020002500 \quad 350055007500 \quad 85009500$

Cut-off ASP particles/ul
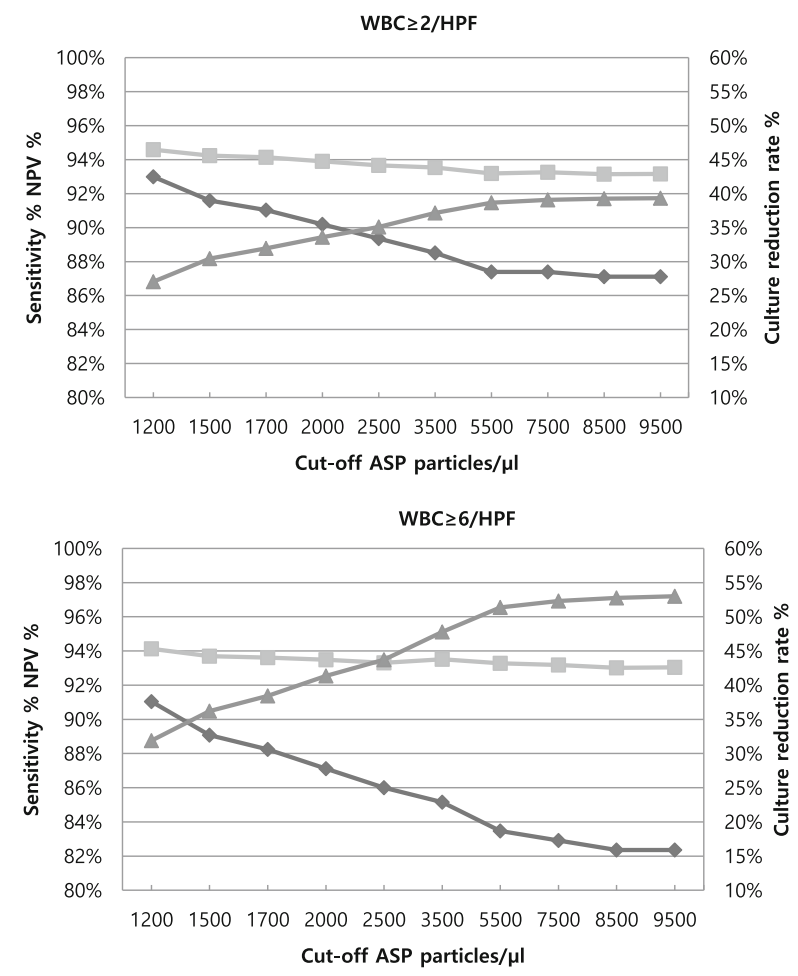

Cut-off ASP particles/ $\mu \mathrm{l}$

Fig. 3 (See legend on next page.) 
(See figure on previous page.)

Fig. 3 Relationship of sensitivity, NPV and culture reduction rate according to the WBC and ASP cut-off values. The grey shadow areas indicate the cut-off value combinations showing acceptable range of NPV $(>97 \%)$ and culture reduction rate $(>50 \%)$. Six combinations that satisfy the acceptable range for detecting uropathogen of $10^{5} \mathrm{CFU} / \mathrm{ml}$ are shown in the presented charts. However, none of the combinations gives acceptable results for detection of $10^{4} \mathrm{CFU} / \mathrm{ml}$. The raw data of the charts are presented in the Additional file 2: Table S1

and culture saving rate of $48.9 \%$ at the combined settings of ASP $\geq 10,000 / \mu \mathrm{l}, \mathrm{WBC} \geq 6 / \mathrm{HPF}$, and few or more bacteria or yeast, at culture positive rate of $25.6 \%$. In the study of Sturenburg et al. [6], at a given sensitivity of $95 \%$, the culture saving rate was $35 \%$ and specificity was $61 \%$ under the various combinations of $\mathrm{ASP}+\mathrm{WBC}+$ $\mathrm{BACT}+\mathrm{NT}+\mathrm{LE}$. However, it is difficult to directly compare the study results, because of the differences in the study designs and patient populations that may affect the distribution of uropathogens (species and concentrations). Furthermore, several investigators have improved performance through reclassification of the captured image by trained technologists [10-13]. In this study, we did not review the captured image for whole specimens because it will be inconvenient in real practice. However, we reviewed the captured images of false negative result, but none of them could be edited to positive result.

We investigated the reasons for poor performance of the parameters in detecting $10^{4} \mathrm{CFU} / \mathrm{ml}$ bacteriuria. Applying the combination of $\mathrm{WBC} \geq 6 / \mathrm{HPF}, \mathrm{ASP} \geq 7500 / \mu \mathrm{l}$, $\mathrm{BACT} \geq 1 / \mathrm{HPF}$ and positive $\mathrm{LE}$, the false negative case numbers for detecting $10^{5} \mathrm{CFU} / \mathrm{ml}$ bacteriuria and $10^{4}$ $\mathrm{CFU} / \mathrm{ml}$ bacteriuria were 21 and 61, respectively. This indicates that $65.6 \%(40 / 61)$ of false negative cases were from samples with $10^{4-5} \mathrm{CFU} / \mathrm{ml}$ bacterial concentration.

It is of note that, Enterococcus spp. $(55.7 \%, 34 / 61)$ was the most common uropathogen causing the false negative results and was followed by Escherichia coli $(23.0 \%$, 14/61), while the most common uropathogen detected was Escherichia coli (40.9\%) and was followed by Enterococcus spp. (36.8\%). In other words, as many as $31.8 \%$ (34/107) of Enterococcus spp.-grown specimens showed false-negative results, whereas only $11.8 \%(14 / 119)$ of $E$. coli- grown specimens showed false-negative results. This is in line with previous reports $[10,14]$, where images of iQ200 module were difficult to interpret as "bacteria", except rod-form bacteria. In addition, E. coli was the most common pathogens among the $10^{5} \mathrm{CFU} / \mathrm{ml}$ bacteriuria, while Enterococcus spp. was the most common pathogen among the $10^{4-5} \mathrm{CFU} / \mathrm{ml}$ bacteriuria. This might be the reason why the performance of the parameters were lower in detecting $10^{4} \mathrm{CFU} / \mathrm{ml}$ compared to $10^{5} \mathrm{CFU} / \mathrm{ml}$. In addition, in this study, growth of Enterococcus spp. accounted for as many as $36.8 \%$ of total culture-positive specimens, which is much higher than those of other studies $(8-20 \%)[6,7,15]$. Most cases of Enterococcus spp. were isolated from patients with hematologic malignancy (about 60-70\%). As our hospital has the largest bone marrow transplantation center in Asia, the high proportion of specimens from the patients with hematologic malignancy might have influenced on the relatively lower sensitivity of this study than other study $[6,7]$.

In detecting WBC among the culture-positive cases, the positive rate of iQ200 was significantly higher than that of Gram stain. This finding is supported by previous studies comparing the iQ200/iChem workstation with the conventional method where $\mathrm{iQ} 200 / \mathrm{iChem}$ workstation showed good correlation in WBC count [10, 11, 14]. Considering that pyuria is an important marker for UTI, detection of WBC by iQ200 will be useful.

Another important issue is the categorical approach for patient population. In this study, the sensitivity of two parameters (WBC and ASP) was less sensitive for specimens from adult women, especially elderly, than that for adult men. One previous study using Symex UF500i flowcytometer [16] also found that bacteria and leukocyte count performed better in men and adult than in women and elderly. This is probably due to the high prevalence of UTI in women and elderly. Although urine culture is not necessary for outpatient with uncomplicated UTIs, it is mandatory for specific populations including elderly, pregnant women, infants, patient with spinal cord injuries, diabetes, underlying urologic abnormalities, immune compromised condition and indwelling urethral catheters [17].

\section{Conclusion}

Based on our results, iQ200/iChem showed high NPV and culture reduction rate with the criteria of $10^{5} \mathrm{CFU} /$ $\mathrm{ml}$ bacteriuria and in detecting pyuria which is the important marker for UTI, the positive rate of pyuria was higher with iQ200 than Gram stain. However, it did not show high enough performance for detecting bacteriuria in concentration of $10^{4-5} \mathrm{CFU} / \mathrm{ml}$, mostly due to Enterococcus species. Taken together, iQ200/iChem workstation can be used for screening of urine specimens to reduce bacterial culture with the exception of specimens from the specific populations mentioned above.

\section{Additional file}

Additional file 1: The raw dataset of 1942 urine samples including patients' gender, age-range, specimen type, and test results from culture, gram staining and iQ200/iChem workstation. (XLSX 251 kb) 
Additional file 2: Table S1. Performance of combined parameters for detection of $10^{5} \mathrm{CFU} / \mathrm{ml}$. (DOCX $28 \mathrm{~kb}$ )

\section{Abbreviations}

ASP: All Small Particles; BACT: Bacteria; BYST: Yeast; CFU: Colony Forming Units; LE: Leukocyte Esterase; NPV: Negative Predictive Value; NT: Nitrite; PPV: Positive Predictive Value; UTI: Urinary Tract Infection; WBC: White Blood Cells

\section{Acknowledgments}

We appreciate Doctor. Youn Jeong Kim, the physician of infectious disease, for the fruitful discussion.

\section{Authors' contributions}

JML and YJP planned the study analyzed the data, JML and EHH collected the data, DJP and GKP performed the experiments and gave the technical support. All authors have read and approved of the final manuscript.

\section{Funding}

This work was supported by a research grant from Korea Health Industry Development Institute (HI16C0443) and Beckman Coulter (Korea). The funding bodies had no role in study design, data analysis and interpretation and preparation of the manuscript.

\section{Availability of data and materials}

All data generated during the current study are included in this published article and its supplementary information file (Additional file 1).

\section{Ethics approval and consent to participate}

This study was approved by the institutional review board (IRB) of Seoul St. Mary's Hospital. The IRB waived the requirement to obtain informed consent from participants, because we used de-identified left over samples obtained from routine examination.

\section{Consent for publication}

Not applicable.

\section{Competing interests}

The authors declare that they have no competing interests.

Received: 1 May 2018 Accepted: 29 May 2019

Published online: 17 June 2019

\section{References}

1. Peleg AY, Hooper DC. Hospital-acquired infections due to gram-negative bacteria. N Engl J Med. 2010;362(19):1804-13.

2. Hines AG, Rupp ME, Van Schooneveld TC. Urinary tract infection and asymptomatic bacteriuria guidance. In: The antimicrobial stewardship program. Committee of the Nebraska Medical center.2014. https://www. nebraskamed.com/sites/default/files/documents/for-providers/asp/uti-asbuguidance-final.pdf Accessed 15 Sep 2018.

3. Shang YJ, Wang QQ, Zhang JR, Xu YL, Zhang WW, Chen Y, Gu ML, Hu ZD, Deng AM. Systematic review and meta-analysis of flow cytometry in urinary tract infection screening. Clin Chim Acta. 2013;424:90-5.

4. Winquist AG, Orrico MA, Peterson LR. Evaluation of the cytocentrifuge gram stain as a screening test for bacteriuria in specimens from specific patient populations. Am J Clin Pathol. 1997:108(5):515-24.

5. Semeniuk H, Church D. Evaluation of the leukocyte esterase and nitrite urine dipstick screening tests for detection of bacteriuria in women with suspected uncomplicated urinary tract infections. J Clin Microbiol. 1999; 37(9):3051-2.

6. Stürenburg E, Kramer J, Schön G, Cachovan G, Sobottka I. Detection of significant bacteriuria by use of the iQ200 automated urine microscope. J Clin Microbiol. 2014;52(8):2855-60.

7. Parta M, Hudson BY, Le TP, Ittmann M, Musher DM, Stager C. IRIS iQ200 workstation as a screen for performing urine culture. Diagn Microbiol Infect Dis. 2013;75(1):5-8.

8. Ronald A. The etiology of urinary tract infection: traditional and emerging pathogens. Am J Med. 2002;113(1):14-9.
9. Leber AL. Clinical microbiology procedures handbook, fourth edition, vol. 2, 4 edn: American society of. Microbiology. 2016.

10. Lamchiagdhase $P$, Preechaborisutkul $K$, Lomsomboon $P$, Srisuchart $P$, Tantiniti P, Khan-u-Ra N, Preechaborisutkul B. Urine sediment examination: a comparison between the manual method and the iQ200 automated urine microscopy analyzer. Clin Chim Acta. 2005;358(1-2):167-74.

11. Linko S, Kouri TT, Toivonen E, Ranta PH, Chapoulaud E, Lalla M. Analytical performance of the Iris iQ200 automated urine microscopy analyzer. Clin Chim Acta. 2006;372(1-2):54-64.

12. Russcher A, Kusters E, Wolterbeek R, Kuijper EJ, Cobbaert CM, van der Beek MT. Interlaboratory collaboration for optimized screening for urinary tract infection. J Clin Microbiol. 2016;54(1):93-8.

13. Luciano R, Piga S, Federico L, Argentieri M, Fina F, Cuttini M, Misirocchi E, Emma F, Muraca M. Development of a score based on urinalysis to improve the management of urinary tract infection in children. Clin Chim Acta. 2012 413(3):478-82

14. Alves L, Ballester F, Camps J, Joven J. Preliminary evaluation of the Iris $\mathrm{IQ}^{\mathrm{TM}}$ 200 automated urine analyser. Clinical Chemical Laboratory Medicine. 2005; 43(9):967-70.

15. Brilha S, Proenca H, Cristino JM, Hänscheid T. Use of flow cytometry (Sysmex ${ }^{\odot}$ UF-100) to screen for positive urine cultures: in search for the ideal cut-off. Clin Chem Lab Med. 2010;48(2):289-92.

16. Yusuf E, Van Herendael B, van Schaeren J. Performance of urinalysis tests and their ability in predicting results of urine cultures: a comparison between automated test strip analyser and flow cytometry in various subpopulations and types of samples. J Clin Pathol. 2016:jclinpath-2016204108.

17. Foxman B. Epidemiology of urinary tract infections: incidence, morbidity, and economic costs. Am J Med. 2002;113(1):5-13.

\section{Publisher's Note}

Springer Nature remains neutral with regard to jurisdictional claims in published maps and institutional affiliations.
Ready to submit your research? Choose BMC and benefit from:

- fast, convenient online submission

- thorough peer review by experienced researchers in your field

- rapid publication on acceptance

- support for research data, including large and complex data types

- gold Open Access which fosters wider collaboration and increased citations

- maximum visibility for your research: over $100 \mathrm{M}$ website views per year

At $\mathrm{BMC}$, research is always in progress.

Learn more biomedcentral.com/submission 